\title{
The Impact of Organizational Justice on Employee Performance: A Case Study of Cantonment Board Employee Peshawar Pakistan
}

\author{
YASIR KHAN \\ Ph.D Scholar, Qurtuba University Peshawar \\ yasirok62@yahoo.com \\ MUHAMMAD AMJAD \\ AG Office Peshawar \\ mamjadpsh@gmail.com \\ AYESHA IRAJ \\ MS-Scholar, Institute of Management Studies, Pesahwar \\ OBAID ULLAH BASHIR \\ MS Scholar, Islamia College University, Peshawar
}

\begin{abstract}
This article examined the impact of Organization Justice on employees' performance in cantonment board Peshawar. The study was conducted using 150 employees as a sample and applied stratified random sampling technique. Statistical techniques i.e reliability analysis, Factor analysis, correlation and Regression applied. The results were obtained using correlation regression to know the direction, association and impact of variables and the effects organization justice on employee's performance. The results found that Organization Justice affects the employee's performance positively Therefore it is suggested that CBP should exercise such justice in the organization which will inculcate more confidence in the employees. All the hypotheses developed for this study has been proved through the analysis of this research study.
\end{abstract}

Key words: Organizational Justice, Employee's Performance, Interactional Justice, Distributive Justice, Procedural Justice.

\section{Introduction}

Organizational Justice (OJ) refers to judgments and behavior individual employees have towards the organization. More precisely it is the perceptions of the employees towards the organization operations and dealing with other organization, employees and competitors in the market place. Organizational justice particularly represents decisions taken by an organization which are based on equity, law and full of fairness. Fairness in the organization always has an impact on the work and attitude of the employees. Fairness in the system help to motivate and make the employees committed towards their work and then they exhibit right behavior in the work environment and contribute to the organization prosperity and growth. Justice in an organization represents the issues which are related to the organization's pay system, promotion, rewards and 
other type of justice. The organizational justice has mainly divided into three sub facets by the researcher i.e distributive justice, procedural justice and interactional justice. These all types have some have influence on the organization's productivity, growth, profitability and the performance of the employees. As the distributive justice states the fairness organization has in its resources and distribution procedures like the fairness in pay, rewards and promotion. It is very vital for the strength and smooth functioning of the organization. An organization do well in term of distributive justice when the outcomes of the organization are equally applied (Adam, 1965).

Procedural Justice seems very vital for the organization as it focuses on the justice and fairness in the process system of an organization and it has vital impact on the organization's outcomes i.e growth, productivity, profitability and improved performance. Another type of justice which is Interactional Justice has also an influence on the employees' performance and their productivity along with other outcomes of the organization. Interactional justice is a kind of justice in term of disseminating information smoothly and quickly and making the employees well informed timely (Bies \& Moag, 1986). Cantonment Board Peshawar (CBP) is providing Municipal services to residents of Peshawar Cantonment. Population of 200,000/- is dependent on this organization which has diversified work force of more than 2000 employees of almost all categories, ethnic groups, different culture, languages, age groups, gender mix, academic level from illiterate to highly qualified personals and variety of skilled labor of different fields. Providing justice to such muilti cultural and ethnic people in the organization is a challenging task. Various studies have been conducted to find the impact of organizational justice on the employee's performance. Hence, the aim of this study is find out the influence of organizational justice on the employees of Cantonment Board Peshawar.

\subsection{Problem Statement}

The proper Implementation of Organizational Justice is always a challenge for the organizations especially in the current dynamic environment. Those organizations which successfully implement these practices can prosper the organization. Cantonment Board is an organization having around 2000 employees can be prosper if it over come the mindset of its employees by offering unique practices of justice. To know the exact level of Organizational Justice in this institution is an issue to be discussed. This research aims to understand the prevailing organizational justice and its effects on employee's performance.

\subsection{Objectives of Research}

Following are the objectives of the research:

- To examine the relationship of Organizational Justice with employees performance.

- To understand and investigate the impact of Organizational Justice on employees performance in Cantonment Board Peshawar (CBP).

- To suggest few measures on the bases of the findings.

\subsection{Research Questions}

- What is the relationship of Organization Justice with employees' performance in Cantonment Board Peshawar (CBP) Peshawar? 
- What is the level of justice practices in Cantonment Board Peshawar (CBP)?

- What effects will carry by Organizational Justice in employees' performance in Cantonment Board Peshawar (CBP)?

\subsection{Significance of Research}

This research study is important because, it covers very important aspects of Human Resource Management in organizations like Cantonment Board Peshawar (CBP). On which very limited studies have been done. This research study will cover three variables organizational justice, Employee Performance and trust. Further the study is going to be done in such sector Cantonment Board Peshawar (CBP). Where no study at all on this area has been done previously; therefore Cantonment Board Peshawar (CBP) will be benefited from this study along with residents of Peshawar Cantonment. CBP will understand the outcomes of its justice system being adhered to in the daily practices of the organization. This study will explore the trust perception of its employees on the Organizations Justice system and will help the CBP to better deal with the prevailing justice practices to boost up the employees trust and confidence and will contribute in the enhanced productivity of the organization. The policy makers for this organization can be better benefited from the results of this research study, as they will address the loop holes and the areas in Organizational Justice, which causes de-motivation and lack of trust of the employees on the processes and procedures of this organization.

\section{Literature Review}

\subsection{Organizational Justice}

As per Ryan (1993) the idea of Organization Justice is extremely antiquated and can be connected with Plato and Socrates period. Yet, the discussion on Organization Justice began from the hypothesis being exhibited by Adam Smith (1963). Greenberg (1990) contended about the significance of Organization Justice as it involves mental wonder which covers the treatment of all workers decently with regards to organization. Cropanzaton (1998) argued that Organization Justice implies comparable and reasonable representative treatment in the association. Authoritative equity was viewed as essential because of the decency in the region of work and after that the subject got significance. Elamin et al (2011) saw that Organization Justice and its hidden effect or the results of the association has helped associations to get this objective and at last to have aggressive edge over different firms having absence of equity practices.

\subsection{Types of Organizational Justice}

Leventhal (1980) found that Procedural Justice is the decency in strategies in regards to appropriation and portions of the Organization. Organizational justice can be expressed in three ways. Erdogan (2002) found that all these three sorts of justices are connected, yet they have diverse and unmistakable measurements.

\subsubsection{Distributive Justice}

It is the employees' perception of fairness in all organizational resources, i.e. fairness in promotion, payments and rewards as expressed in value hypothesis that workers see reasonable prizes framework in an association, Folger and Konovsky (1989). Greenberg (1990) contended that distributive equity is more about the reasonableness in prizes and motivators being gotten by the representatives for their commitments for the association. 


\subsubsection{Procedural Justice}

It simply means the fairness in the procedures of the organization. Greenberg (1990) contended that the basic leadership and authoritative methodology got auxiliary significance with regards to the association. Farahbod et al (2012) expressed that Procedural Justice is about the representatives' discernment about the reasonableness in various strategies and rules being included in the basic leadership procedures of the association. Leventhal (1980) recommended that reasonableness in process can be influenced by different variables too. Like consistency control, predisposition concealment manage, and different standards like precision, right capacity, representativeness and ethicality run the show. The consistency decide tells that assignment systems ought to be predictable crosswise over people and after some time. The predisposition concealment decide tells that individual self-enthusiasm of individual ought to be avoided.

\subsubsection{Interactional Justice}

Bies and Moag (1986) developed this concept, and argued that fair interpersonal treatment being received by employees is also important area of concern for the researchers in organizational proceduresSo the decency in interpersonal treatment is named as IJ. Bies and Moag (1986) presented the measurements of interactional equity, which speak to the quality in interpersonal treatment which is being normal from the systems being actualized. The significance is the decency criteria of interpersonal correspondence" (Bies and Moa, 1986: Bies 1987 Tyler and Bies, 1990). Interactional equity is the most imperative part of authoritative exercises. It is extremely connected with association exercises and has affect on correspondence. Cobb, Vest and Hills (1997) contended that discernment about reasonableness is appeared by the pioneer . Interactional Justice can be said exceptionally imperative for the feeling, conduct and individual change. These components truly bring change ( Bies and Moag ,1986). Colquitt et al (2001) surveyed that there is key relationship between the trust and individual feeling. Bury individual treatment is being gotten through these reasons, Tayler (1989).

\subsection{Organizational Justice and Firm Performance}

Khaliq et al, (2012) led an examination in keeping money division and found that the part of Organization Justice is key with regards to any association. They found that keeping money area concentrating on frameworks which enhance equity and on the other hand it will build the workers' fulfillment level toward association. Altaf et al (2011) analyzed the Interactional Justice with regards to association and found that administration should be very much aware of the client inclinations and the result of the clients plan. The workers apply their abnormal state of duty just on the off chance that they are fulfilled from the equity of the association or they have trust on the overarching Justice arrangement of the association. 


\subsection{Theoretical Frame Work}

Theoretical frame work is very essential for any research. This research study is conducted with the following conceptual framework, which clearly shows the relationship of dependent and independent variables.

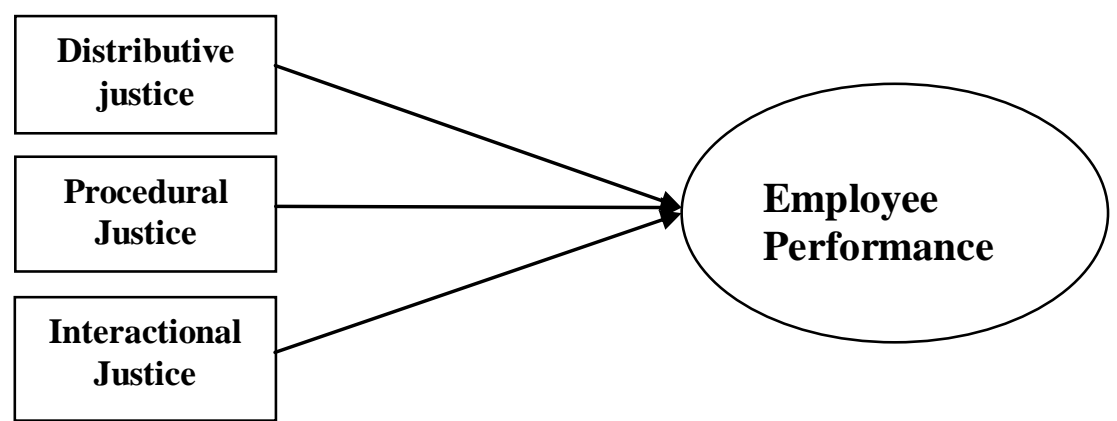

Figure 1: Theoretical Framework

This study is focused on the three dimensions of Organizational Justice i.e Distributive justice, Procedural Justice and Interactional Justice as Independent Variables and Employee Performance as dependent variable.

\subsection{Research Hypotheses}

This research study is based on the following research hypotheses framed with the help of the previous literature.

$H_{1}$. Distributive justice has positive impact on the employees' performance.

$\mathrm{H}_{2}$. Procedural justice has positive impact on employees' performance.

$H_{3}$. Interactional justice has positive impact on employees' performance.

\section{Research Methodology}

This chapter tells about the tools used for the analysis of data, methods of collecting data and the analysis of data. Further this chapter provides the detail the selection of respondents and the data being collected from different employees in the organization to use true representative of the whole population. In this part the questionnaire validity and reliability have been discussed.

\subsection{Research Design}

Bryman and Bell (2007) asserted that design of the research is very vital which helps to conduct the research via data collection and the analysis of the study. Saunders et al (2009) asserted the experimental research helps in better understanding of a phenomenon representing the relationship among various variables. Collis and Hussey (2009) asserted that a case study helps to be based on a case and the longitudinal study helps to find out the impact of a variable on another in different time period. Saunders et al (2009) argued that cross sectional type of the research is also helpful to analyzed a specific phenomenon. This is a kind of correlational or explanatory study.

\subsection{Type of the Research}

This study is a kind of quantitative study due to the fact that the results have been quantified based on the sample. 


\subsection{Population and Sample of Research}

Saunders et al (2009) asserted that sample is very much essential and argued that the huge sample helps in better results of the research. He also argued that huge sample take more time and funding on the other hand as well. Anderson and Tatham (1998) confirmed that 100 observation need to there in any research study to have proper significant results. The population in this particular study represents all employees of all level in this organization (CBP). The research was conducted on stratified sampling bases, as different type of employees working in the structure of CBP and so that to get representative from each status. Total 150 employees of different sections were inquired for this study.

\subsection{Sources of Data and Data Collection}

As there are many methods available for the collection of data, i.e. observation method, questionnaire, group discussion and different forms of structured, unstructured and semi structured interviewee. Sanders et al (2009) argued that there are two type of methods of dealing with questionnaires, i.e. sending it by mail and getting back by mail after being fulfilled by respondents and second method is by handing over and getting back in person after being fulfilled by respondents. Wuensch and Karl (2005) argued that Likert scale is mostly used in social sciences to measure the attitude and behaviors of the respondents. Burn, Alvin and Ronald (2008) found that Likert scale contains from strongly agree to strongly disagree for getting the intensity of feeling of the respondents in the given scenario. For this research study primary data was collected, using questionnaires on five Liker Scale, starting from strongly agree to strongly agreed. The responses collected from the respondents of this study, who are the employees Cantonment Board Peshawar. Usually for any research study the following techniques of data collections are used.

\subsection{Tools for Data Analysis}

As measurable and verifiable data was obtained for this research study. Statistical Software Packages for Social Sciences (SPSS) used for the data analysis of this research study.

\subsection{Statistical Techniques}

Descriptive statistics, correlation, regression, and questionnaire reliability and validity techniques applied in this research study to get true and exact results of this research study. Factor analysis was applied for inter correlation of the variables used.

\subsection{Factor Analysis}

Factor analysis is used to understand the inter correlation among questions in a factor or a variable. Ghauri and Gronhaug (2010) argued that factor analysis is conducted to understand the correlation structure among various variables. Liuva and salvend (2009) stated that two types of factor analysis being used, one is exploratory factor analysis and the other is confirmatory factor analysis. The exploratory type of factor analysis is the most important one and mostly used one as in it the researcher explains the structure of so many variables at the same time whereas the confirmative factor analysis is used to find the compatibility among various variables which are usually extracted through statistical analysis. In this research study explanatory factor analysis has been used. It was 
conducted to reduce the number of factor which has no inter correlation with the rest of questions in the same variable and that to smooth the way for the analysis.

\subsection{Cronbach's Alpha Test}

Cronbach's alpha test is used to test the internal consistency or reliability of measurements. Cronbachs alpha is usually used in behavioral and social researches as being the prominent indicator of the reliability (Liu, Zumbo \& Wu,2010). In this research study the Cronbach's test applied to test the reliability of the measurements comprised in the factors. Nunnaly (1978) suggests that the value of Cronbach's alpha test should be at least 0.7 to be confident that the measurements are reliable. But some of the statisticians believe that it can be acceptable even if it is above 0.6(Shelby, 2011).

\subsection{KMO and Bartlett's Test}

KMO and Bartlett's tests have been applied in this research study to know the adequacy of sample size in this research study. KMO test suggest that the value of this test should be 0.5 or above. As Kaiser (1974) argued that accept the value of 0.5 and if less than this then collect more data for the research. The KMO value is above the suggested value by the researcher; hence the sample size is considered enough to carry the further statistical analysis of this research study.

\section{Data Analysis and Discussion}

\subsection{Reliability Analysis}

Reliability test is used for knowing the internal consistency in data. If data is reliable than further it is called as feasible data for conducting further analysis.

Table 1 Reliability Analysis ( $=150)$

\begin{tabular}{|lll|}
\hline & Total Number of Items & Cronbach's Alpha \\
\hline Distributive Justice & 4 & 0.81 \\
Procedural Justice & 5 & 0.75 \\
Interactional Justice & 4 & 0.70 \\
Employee Performance & 7 & 0.71 \\
\hline
\end{tabular}

Factor analysis, KMO and Bartlettest for Distributive Justice

\begin{tabular}{|cc|}
\hline Sig. & .000 \\
\hline
\end{tabular}

The above results indicating the reliability values of all variables used in the data analysis of the study. The obtained values of all these variables are above than the acceptable ranges i.e 0.60 or above. All variables i.e Procedural Justice, Distributive Justice, Interactional Justice and Employees Performance have more cronbach's alpha values than the thresh hold value. Researchers believes that any chronbach value of 0.60 
or above is acceptable in social researches, hence all variables have more values than the thresh hold.

\subsection{Factor Analysis, KMO \& Bartlett's Test}

As reliability has been used for the internal consistency and the factor analysis is used for the intercorrelation in the questions and validity of the questions of the construct. The KMO and Bertlet tests have been applied for the understanding of the sample sufficiency and adequacy.

Table 2: KMO and Bartlettest of distributive Justice ( $N=150)$

\begin{tabular}{|lll|}
\hline Kaiser-Meyer-Olkin Measure of Sampling Adequacy. & .780 \\
\hline \multirow{3}{*}{ Bartlett's Test of Sphericity } & Approx. Chi-Square & 112.803 \\
& Df & 149 \\
\end{tabular}

\begin{tabular}{|c|c|}
\hline \multicolumn{2}{|c|}{ Table 3: Component Matrix Distributive Justice (N=150) } \\
\hline & Component 1 \\
\hline Q1 & .66 \\
\hline Q2 & .61 \\
\hline Q3 & .52 \\
\hline Q4 & .80 \\
\hline
\end{tabular}

The above tables indicating the results of KMO \& Bartlett's test and components matrix of a variable. The DJ has been checked for all of its four items. The results indicatetes that there is enough intercorelation in all questions of this variable. The acceptable value of a question in a factor is .50 or above. All the questions in factor DJ have been properly loaded well above the desired level of intercorrelation. KMO and Bartlett's value seems very significant which means that sample used in this study is enough for farther analysis. 


\subsubsection{Factor Analysis, KMO and Bartlet est for PJ}

Table 4KMO and Bartlett's Test of Procedural Justice $(N=150)$

\begin{tabular}{|lll|}
\hline Kaiser-Meyer-Olkin Measure of Sampling Adequacy. & .619 \\
\hline & Approx. Chi-Square & 102.043 \\
Bartlett's Test of Sphericity & Df & 149 \\
& Sig. & .000 \\
\hline
\end{tabular}

Table 5: Component Matrix of Procedural Justice( $\mathrm{N}=150)$

\begin{tabular}{|lc}
\hline Component 1 & \\
\hline Q5 & .63 \\
Q6 & .73 \\
Q7 & \\
Q8 & .56 \\
Q9 & .78 \\
\hline
\end{tabular}

The above tables indicating the results of KMO \& Bartlett's test and components matrix of a variable procedural justice. The PJ has been checked for all of its four items. This indicates that there is enough intercorelation in all questions of this variable. The acceptable value of a question in a factor is .50 or above. All the questions in factor PJ have been properly loaded well above the desired level of intercorrelation. KMO and Bartlett's value seems very significant which means that sample used in this study is enough for farther analysis. 


\subsubsection{Factor analysis, KMO and Bartlet Test for IJ}

Table 6: KMO and Bartlett's Test of Interactional Justice ( $N=150)$

Kaiser-Meyer-Olkin Measure of Sampling Adequacy.

Approx. Chi-Square

Bartlett's Test of Sphericity

Df

Sig.

Table 7: Component Matrix of Interactional Justice (N=150)
Component 1

Q10

Q11

Q12

Q13
.718

92.901

.000

The above tables indicating the results of KMO \& Bartlett's test and components matrix of a variable Interactional justice. The IJ has been checked for all of its four items. The results indicate that there is enough inter correlation in all questions of this variable. The acceptable value of a question in a factor is .50 or above. All the questions in factor IJ have been properly loaded well above the desired level of inter co relation. KMO and Bartlett's value seems very significant which means that sample used in this study is enough for further analysis.

\subsubsection{Factor Analysis, KMO and Bartlett's Test for Employees performance}

Table 8: KMO \& Bartlett's Test for Employees performance $(\mathrm{N}=150)$

\begin{tabular}{|lll|}
\hline Kaiser-Meyer-Olkin Measure of Sampling Adequacy. & .862 \\
\hline & Approx. Chi-Square & 105.722 \\
Bartlett's Test of Sphericity & & \\
& Df & 149 \\
& Sig. & .000 \\
\hline
\end{tabular}


Table 9: Component Matrix for Performance ( $N=150)$

\begin{tabular}{|ll|}
\hline & Component 1 \\
\hline Q14 & .65 \\
Q15 & .56 \\
Q16 & .79 \\
Q17 & .60 \\
Q18 & .54 \\
Q19 & .89 \\
Q20 & .56 \\
\hline
\end{tabular}

The above tables indicating the results of KMO \& Bartlett's test and components matrix of a variable employee performance. The employee performance has been checked for all of its four items. The results indicatetes that there is enough intercorelation in all questions of this variable. The acceptable value of a question in a factor is .50 or above. All the questions in factor EP have been properly loaded well above the desired level of intercorrelation. KMO and Bartlett's value seems very significant which means that sample used in this study is enough for farther analysis.

\subsection{Correlation Analysis}

Table 10: Correlation analysis of the variable $(\mathrm{N}=150)$

\begin{tabular}{|lllll|}
\hline & DJ & PJ & IJ & $\begin{array}{l}\text { Employees } \\
\text { Performance }\end{array}$ \\
\hline DJ & 1 & & & \\
PJ & $.686^{* *}$ & 1 & 1 & \\
IJ & $.589^{* *}$ & $.610^{* *}$ & & 1 \\
$\begin{array}{l}\text { Emplo } \\
\text { yees }\end{array}$ & $.560^{* * *}$ & $.566^{* *}$ & $.653^{* *}$ & \\
$\begin{array}{l}\text { Perfor } \\
\text { mance }\end{array}$ & & & & \\
\hline
\end{tabular}

**. Correlation is significant at the 0.01 level (2-tailed).

The above results indicating the correlation matrix of independent variables with dependent variable. The results have shown that the DJ has positive and significant correlation with the employees' performance. Similarly the results also showing significant and positive correlation of PJ and IJ with employees' performance. It means that with an increase in these facets of organizational justice, the employees' performance will tend to increase. 


\subsection{Regression Analysis}

4.5.1 Regression Analysis for Distributive Justice and Employees Performance Table 11: Employees Performance Predictor

\begin{tabular}{|llllllll|}
\hline \multicolumn{2}{|c}{$\mathrm{B}$} & $R^{2}$ & Adj $\mathrm{R}^{2}$ & $\Delta \mathrm{R}^{2}$ & F. Value & $\mathrm{T}$ Value & P. Value \\
\hline $\begin{array}{l}\mathrm{D} \\
\mathrm{J}\end{array}$ & 0.475 & 0.314 & 0.308 & - & 59.860 & 7.737 & 0.000 \\
\hline
\end{tabular}

The above result shows the effect of DJ on employee performance. The results showing $\mathrm{R}^{2}$ showing that $\mathrm{PJ}$ causes about 31 percent changes in employees performance. The results also documented well high F-value than 4 which means that the over all model is fit and significant.

\subsubsection{Regression Analysis for Procedural Justice and Employees Performance}

\begin{tabular}{|llllllll|}
\hline \multirow{2}{*}{ Predictor } & \multicolumn{7}{l|}{ Employees Performance } \\
\cline { 2 - 7 } & $\mathrm{B}$ & $R^{2}$ & Adj $\mathrm{R}^{2}$ & $\Delta \mathrm{R}^{2}$ & F. Value & T-Value & P. Value \\
\hline PJ & $\begin{array}{l}0.56 \\
6\end{array}$ & 0.21 & 0.316 & - & 61.860 & 7.86 & 0.000 \\
\hline
\end{tabular}

The above result shows the effect of PJ on employee performance. The results showing $\mathrm{R}^{2}$ showing that $\mathrm{PJ}$ causes about 21 percent changes in employees performance. The results also documented well high F-value than 4 which means that the overall model is fit and significant

\subsubsection{Regression Analysis for Interactional Justice and Employees Performance Relationship}

\begin{tabular}{|lllllllll|}
\hline \multirow{8}{*}{ Predictor } & \multicolumn{7}{l|}{ Employees Performance } \\
\cline { 2 - 8 } & B & R2 & $\begin{array}{l}\text { Adj } \\
\text { R2 }\end{array}$ & $\Delta$ R2 & F. Value & T- & P. \\
IJ & 0.656 & 0.567 & 0.564 & - & 171.831 & 9.000 & 0.000 \\
\hline
\end{tabular}

The above result shows the effect of IJ on employee performance. The results showing $\mathrm{R}^{2}$ showing that $\mathrm{IJ}$ causes about 56 percent changes in employees performance. The results also documented well high F-value than 4 which means that the overall model is fit and significant 


\begin{tabular}{|lll|}
\hline & \multicolumn{2}{c|}{ Collinearity Statistics } \\
\hline & Tolerance & VIF \\
DJ & .867 & 1.131 \\
PJ & .776 & 1.229 \\
IJ & .855 & 1.213 \\
\hline Dependent Variable: Employee performance & \\
\hline
\end{tabular}

The above table clearly shows the multi collinearity analysis of this research study. The results of this study show the values tolerance and VIF within feasible ranges as per the suggestions of ( $\mathrm{O}^{\prime \prime}$ Brien \& Robert, 2007). The above tolerance values reflects that the tolerance level is moderate and good and the VIF values are 1.131, 1.229 and 1.213 which shows that the

VIF level is also good and there is no any problem of multi co linearity.

\subsection{Discussion}

The Value of Cronbach's Alpha regarding this thesis of all variables are well above than the desired level and having more than .60. As the researchers proved that the more the alpha value the more the reliable the data about the particular variable. The results indicated that all questions of the different variables loaded at the values above than the desired level. All questions of the four variables loaded at values above 0.5 and the KMO and Bertlet tests of these construct also showing value above the desired level which indicated that the sample used is proper enough and ample. Results of descriptive portion also documenting that proper standard deviation and maximum and minimum values, which means that the data is normal.

\subsection{Conclusion}

This research has been conducted to find the impact of organizational justice on the employees performance of CBP employees. The research used stratified random sampling technique, analyzing 150 employees of this organization. The research analyzed the data through different statistical techniques, i.e reliability, factor analysis, descriptive statistics, correlation and regression. The results reported that the organizational justice facets have positive significant impact on the employees' performance of this organization employee. The results reported that employees' performance can be enhanced by focusing on the justice system of this organization. The results reported that distributive justice has positive significant impact on employees' performance. The results also reported that procedural justice along with interactional justice has positive significant impact on employees' performance of this organization

\subsection{Future Research}

Following are recommendations for future researchers

- The target population chosen in this research were all the employees of Cantonment Board Peshawar. Future researchers might select any other population for conducting the subject study where the perception of justice procedures and all kinds of processes will be different. 
- Future researcher could take another a moderator on the relationship between Organizational Justice and Employees performance like organizational commitment. The researchers can also use the Organizational politics as well in the the Organizational Justice and employees performance relationship. This was an academic research and for the measurements of variables foreign constructs were adopted. It is better to construct and develop questionnaires by local researchers which will enhance the reliability of the questionnaire.

- Time was another limitation factor which did not give the researcher enough time to meet the respondents individually during the course of the research.

\section{References}

Alvi, A. K., \& Abbasi, A. S .(2012). Impact of OJ on Employee Engagement in Banking Sector of Pakistan. Middle-East Journal of Scientific Research, 12(5),643-649.

Aghaei, N., Moshiri, K., \& Shahrbanian, S. (2012). Relationship between OJand job burnout in employees of Sport and Youth Head Office of Tehran.Advances in Applied Science Research, 3(4).

Altaf, M., Afzal, H., Hamid, K., \& Jamil, M. (2011). Empirical analysis of OJ towards employee's customer oriented behavior: A case study of Medical Institutions in Pakistan. African Journal of Business Management, 5(4), 1286-1292

Boe, T. A. (2002). Gaining and/or maintaining employee trust within service organizations (Doctoral dissertation, University of Wisconsin).

Bond, J. T., \& Galinsky, E. (2006). How Can Employers Increase the Productivity and Retention of Entry Level, Hourly Employees. Research Brief, 2

Choudhry, N., Philip, P. J., \& Kumar, R. (2012). Impact of OJ on Organizational Effectiveness. Industrial Engineering Letters, 1(3), 18-24.

Hassan, M., \& Semerciöz, F. (2010). Trust In Personal And Impersonal Forms Its Antecedents And Consequences: A Conceptual Analysis Within Organizational Context. International Journal of Management \& Information Systems, 14(2).

Ince, M., \& Gül, H. (2011). The Effect of Employees' Perceptions of OJ on Organizational Citizenship Behavior: An Application in Turkish Public Institutions. International Journal of Business and Management, 6(6), 134-149.

Jawad, M., Raja, S., Abraiz, A., \& Malik, T. (2012). Role of OJ in organizational commitment with moderating effect of employee work attitudes, 5(4), 39-45.

Kim, Y., \& Lee, B. G. (2013). An Analysis for the Mediating Effect of OJ on the Performance in the Virtual Organization. International Journal of Software Engineering \& Its Applications, 7(1).

Karim, F., \& Rehman, O. (2012). Impact of Job Satisfaction, Perceived OJ and Employee Empowerment on Organizational Commitment in Semi-Government Organizations of Pakistan. Journal of Business Studies Quarterly, 3(4).

Krot, K., \& Lewicka, D. (2012). The Importance of Trust in Manager-Employee Relationships. International Journal of Electronic Business Management, 10(3). 
Kromhout, P. J. (2011). The Effect of Media Usage, Trust, and Relations on the Productivity, Innovativeness and Flexibility of Teleworkers, and how Knowledge Sharing and Telework Frequency Influences These Relationships. Erasmus Universiteit.

Leblebici, D. (2012). Impact Of Workplace Quality On Employee's Productivity: Case Study Of A Bank In Turkey. Journal of Business, Economics \& Finance, 1(1).

Leow, K. L., \& Khong, K. W. (2009).The study of mentoring and leader-member exchange (LMX) on organizational commitment among auditors in Malaysia. Sunway Academic Journal, 6, 147-172.

Lee, H. R. (2000). An empirical study of OJ as a mediator of the relationships among leader-member exchange and job satisfaction, organizational commitment, and turnover intentions in the lodging industry (Doctoral dissertation, Virginia Polytechnic Institute and State University

Lam, S. S. K., Schaubroeck, J., \& Aryee, S. (2002). Relationship between OJ and employee work outcomes: a cross-national study. Journal of Organizational Behavior, 23(1), 1-18.

Misra, P., Rana, N., \& Dixit, V. (2012). Compensation: Impact of Rewards, Organizational Justice on Job Satisfaction and Turnover Intentions in Retail Store Operations-A Study of Delhi and NCR. In Proceedings of International Conference on Business Management \& IS (No. 1)

Malik, M. E., \& Naeem, B. (2011). Role of perceived OJ in job satisfaction: Evidence from higher education institutions of Pakistan. Interdisciplinary journal of contemporary research in business, 3(8), 662-673

Rostamzadeh, N., Mehri, K., Chelcheleh, A., \& Gholian, H. (2013). The Relationship of OJ and Commitment with Human Resources Productivity in the Offices of Sports and Youth, 2(3), 227-231.

Seyedi, S. M., Dalvand, M. R., Shahidi, N., \&Zohdi, M. H. (2012). Studying Relationship between OJ and Climate with Mental Health. International Proceedings of Economics Development \& Research, 37.

Seok, C.B., \& Chiew, T. C.(2013). Trust trustworthiness and justice perception toward the head of department. Global Journal of Arts Humanities and Social Sciences, 1(1), 20-29

Saher, N., Naz, S., Tasleem, I., Naz, R., \& Kausar, S. (2013). Does Paternalistic leadership lead to Commitment? Trust in leader as moderator in Pakistani context. Interdisciplinary Journal of Contemporary Research in Business, 5(1), 443-455.

Tzafrir, S. S., Baruch, Y., \& Dolan, S. L. (2004). The consequences of emerging HRM practices for employees' trust in their managers. Personnel Review, 33(6), 628647.

Usmani, S., \& Jamal, S. (2013). Impact of DJ, PJ, IJ, Temporal Justice, Spatial Justice on Job Satisfaction of Banking Employees

Vigoda, G., E., \& Talmud, I. (2010). Organizational politics and job outcomes: The moderating effect of trust and social support. Journal of Applied Social Psychology, 40(11), 2829-2861. 
Warokka, A., Gallato, C., \& Moorthy, T. (2012). OJ in Performance Appraisal System and Work Performance: Evidence from an Emerging Market. The Journal of Human Resources Management Research, 1-18.

Yahya, S., Danesh, S., \& Zamani, A. (2012). The Relationship between Perception of OJ and Employee Empowerment in Industrial Town of Rasht, 2(11), 11690-11695.

Zhang, Y., \& Pussadee P., D., B. A. (n.a). The Effect of Organizational Culture and OJ on Employee Satisfaction and Organizational Commitment in Bangkok, Thailand.

Zwick, T. (2004). Employee participation and productivity. Labour Economics, 11(6),715740. 